\section{Pollination Potential of the Bee Osmia aglaia for Cultivated Red Raspberries and Blackberries (Rubus: Rosaceae)}

\author{
James H. Cane \\ U.S. Department of Agriculture, Agricultural Research Service, Bee Biologyand \\ Systematics Laboratory, Utah State University, Logan, Utah 84322-5310
}

Additional index words. Apiformes, Apoidea, brambles, cane fruit, fruit size, Megachilidae, pollinator

Abstract. A manageable cavity-nesting bee, Osmia aglaia Sandhouse (Apiformes: Megachilidae), was evaluated as a pollinator for cultivated red raspberry and blackberries. Floral visits by free-flying honey bees or by less numerous caged $\boldsymbol{O}$. aglaia yielded red raspberry fruit ('Canby' and 'K81-6') of equivalent size. These fruit were 30\% larger (1.9 g, 70 drupelets) than fruit from unvisited flowers. Female $O$. aglaia readily visited flowers of all eight diverse blackberry cultivars observed. For all of these cultivated Rubus, female $\boldsymbol{O}$. aglaia were observed to invariably collect pollen while pivoting atop the brush of pistils, maximizing opportunities for pollen transfer. Within its native geographic range in western Oregon and California, this effective native pollinator could be a sustainably managed, economical bee for cultivated cane fruit.

Fruit production by cultivated cane fruit benefits from pollinator visitation. Wild red (Rubus idaeus L.) and black (R. occidentalis L.) raspberries are diploid, sexual and selfincompatible, but their cultivated derivatives are all self-fertile (Jennings, 1988). Cultivated blackberries are likewise self-fertile, but typically they are polyploids derived from complex crosses of true blackberries and red raspberries (Jennings, 1988). Some self- or autopollination occurs with many of these cultivars, whereby stigmas of outer pistils passively pick up pollen from contact with the surrounding ring of stamens. Fruit can form thereafter, but floral morphologies of raspberries and many blackberries (Nybom, 1986) preclude complete autopollination, because the centermost pistils are never touched by anthers. Without a pollinator, the resulting fruit is smaller and sometimes malformed, owing to a terminal tuft of leathery or dry seedless pistils (Free, 1993; McGregor, 1976) that renders the fresh fruit unmarketable.

A limited diversity of native bees are reported to predominate among floral visitors to wild Rubus (Hansen and Osgood, 1983) despite copious rewards of nectar (reviewed in Free, 1993) and nutritious pollen (Schmidt

Received for publication $17 \mathrm{Feb} .2005$. Accepted for publication 27 Apr. 2005. I am grateful to Brandon Willis and Craig Floyd of Laketown, Utah, for supporting these experiments in their commercial raspberries at Bear Lake, to the OSU Southern Oregon Research and Extension Center for access to their demonstration gardens, and especially to Ron von der Hellen for sharing his experience and populations of $O$. aglaia. Field work was ably assisted by Faye Rutishauser, Don Veirs, Carole Scofield and Morgan Yost. Chad Finn, Cory Sheffield, William Kemp, and anonymous reviewers provided helpful reviews. Corporate names are provided for the convenience of the reader. Such use does not constitute an official endorsement or approval by the USDA or the ARS of any product to the exclusion of others that may be suitable. Bertol.). Photo by Steve Werblow, Homestead Magazine. five species of Osmia and eight other species of Megachilidae at wild $R$. idaeus flowers, none of them common.

Wild bees are also often present in cultivated Rubus plantings, but their numbers are often inadequate for satisfactory pollination service (MacKenzie and Winston, 1984; Winston and Graf, 1982). Therefore, farmers rent colonies of European honey bees (Apis mellifera L.) to pollinate their raspberries and blackberries (McGregor, 1976). Providing honey bees in adequate numbers to ensure good pollination requires three to four colonies per hectare (McGregor, 1976) and favorable weather (Willmer et al., 1994). The annual honey bee rental cost for Oregon cane fruit in 2003 was $\$ 70.00 /$ ha (Burgett, 2004). Rental fees have increased $50 \%$ in the past 10 years (Burgett, 2004), and were sharply increased in 2005. Larger growers rent colonies from migratory beekeepers. Servicing smaller growers may be impractical for these large migratory beekeepers, however. In the past, smaller growers no doubt benefitted from feral honey bee colonies as well as hives supplied by local part-time or hobbyist beekeepers. More recently, Old World mites have decimated populations of feral honey bees, greatly diminishing the ranks of small-time beekeepers, and increased costs for migratory beekeepers. An alternative pollinator for cultivated Rubus is therefore desirable, one that is effective, manageable, and affordable. Alternative pollinators are not currently used, although two manageable species (Osmia cornuta in Italy and O. lignaria in Canada) showed promise when bloom was advanced to match these bees' earlier spring emergence (Pinzauti et al., 1997, S. Javorek personal communication).

In this study, another nonsocial cavity-nesting bee of this genus, Osmia aglaia Sandhouse (Apiformes: Megachilidae), was evaluated for its ability to pollinate cultivated red raspberries and blackberries. Museum records (250 locations, 1400 specimens) show this bee species

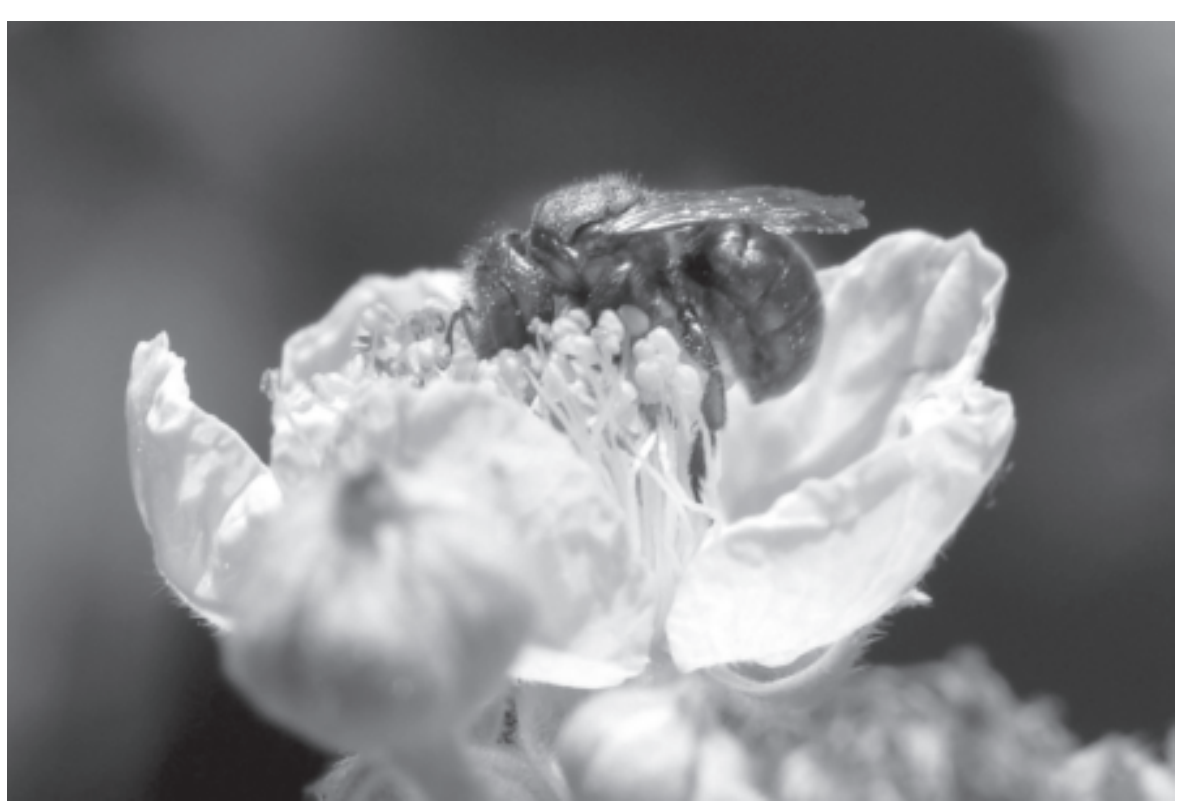

Fig. 1. The bee Osmia aglaia Sandhouse foraging at a flower of Himalaya blackberry (Rubus praecox 


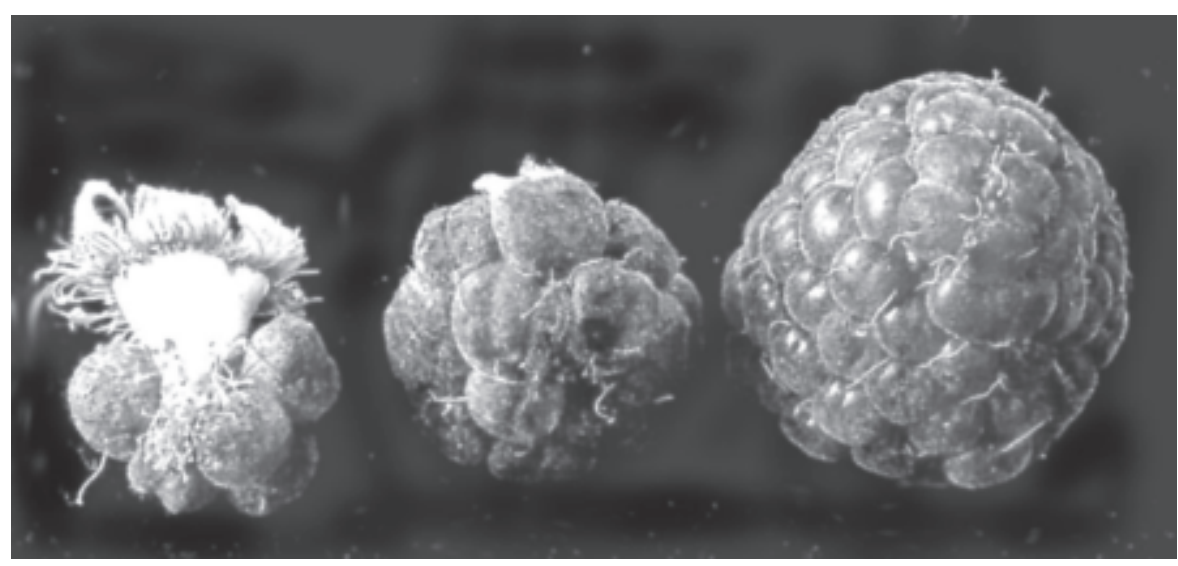

Fig. 2. Fruit of 'Canby' red raspberry chosen to show their smaller girths and fewer drupelets that result when bees were excluded (left two fruit) than when flowers were accessible to bees (right fruit).

to be native to regions of western Oregon and California, including areas with cultivated raspberries and blackberries. Large populations of $O$. aglaia have been trap-nested in western Oregon where feral Himalaya blackberries grow ( $R$. praecox Bertol. or $R$. procerus Muell.); resulting managed generations have increased amid commercial cane fruit, to be detailed in a subsequent report. In this study, O. aglaia were compared with honey bees for their respective pollination efficacies, their floral handling behaviors relevant to pollination, and their cultivar preferences.

\section{Materials and Methods}

Foraging behaviors. Female O. aglaia were observed as they foraged at flowers of cultivated red raspberries and blackberries in 2001 (Fig. 1). The bees' cultivar choices, their stances on flowers, and their floral handling tempos (visitation rates) were recorded. Detailed floral handling data at red raspberry flowers were obtained for nesting females of $O$. aglaia confined to large field cages and honey bees foraging in adjacent rows at Logan and at Bear Lake, Utah. In Oregon, blackberry flower visits by freely foraging honey bees, bumble bees (Bombus vosnesenkii Rad.) and O. aglaia were concurrently observed at a small trial planting of diverse Rubus cultivars planted at the Oregon State University Research and Extension Center in Jacksonville (near Medford). Eight cultivars of hybrid blackberries were in bloom-'Black Butte', 'Boysen', 'Everthornless', 'Logan', 'Marion', 'Olallie', 'Silvan', and 'Tayberry' - as well as two red raspberry cultivars, 'Algonquin' and 'Fallgold'. A nest shelter populated with $O$. aglaia was placed $20 \mathrm{~m}$ away from the trial plots.

Pollination. Foraging honey bees and $O$. aglaia were twice compared for their contribution to red raspberry fruit size at a commercial raspberry farm south of Bear Lake in Laketown, Utah. Because O. aglaia is not native to Utah, nesting females had to be confined to a $50 \mathrm{~m}^{2} \times 2-\mathrm{m}$ high square cage of 20-mesh Lumite polypropylene (Synthetic Industries Inc., Chicopee, Georgia) set over two rows of red raspberries. Outside the cage, commercial honey bee colonies furnished foragers in nearby rows. Each cage was stocked with a wooden cultivar tested at the farm, 'Canby'.

Statistical analysis. Differences in fruit size between unvisited bagged controls in and out of the cage (cage effect) were first compared using $t$ tests for drupelet counts and for fruit weights. Drupelet counts and fruit weights were then used for separate general linear models ANOVAtests (SAS Institute, 1989). Data were confirmed to be normal; their variances were nearly identical. If significant overall, then planned orthogonal comparisons (Sokal and Rohlf, 1995) were used to test for an effect of bee visitation on fruit size (bagged vs. accessible to bees) and for treatment differences between $O$. aglaia and honey bees. Means \pm $1 \mathrm{SD}$ are given in the text.

\section{Results}

Foraging behaviors. Female O. aglaia willingly visited flowers of all blooming raspberry (2) and blackberry (8) cultivars at the small experimental plot in Jacksonville, Ore. Flowers of most of these cultivars were also visited by worker honey bees and bumble bees. The stance of female O. aglaia while handling Rubus flowers ensured contact with all stigmas. At flowers of the red raspberry 'Canby' growing in Utah, female ( $n=240$ visits) and male $O$. aglaia (65 of 66 visits) always stood astride the central pistils, pivoting in a circle as they probed for nectar and harvested pollen $(30$ daily observations between $10 \mathrm{AM}$ and $6 \mathrm{PM}$ over three weeks). In contrast, nectar-foraging honey bees were often seen to walk in a circle about 'Canby' flowers, following the ring of nectaries and outer stamens, but failing to contact the more central pistils. Honey bees and $O$. aglaia worked red raspberry flowers at comparable speeds ( $10.5 \mathrm{vs.} 11$ seconds/flower, $n=46$ and 112 floral visits, respectively). At

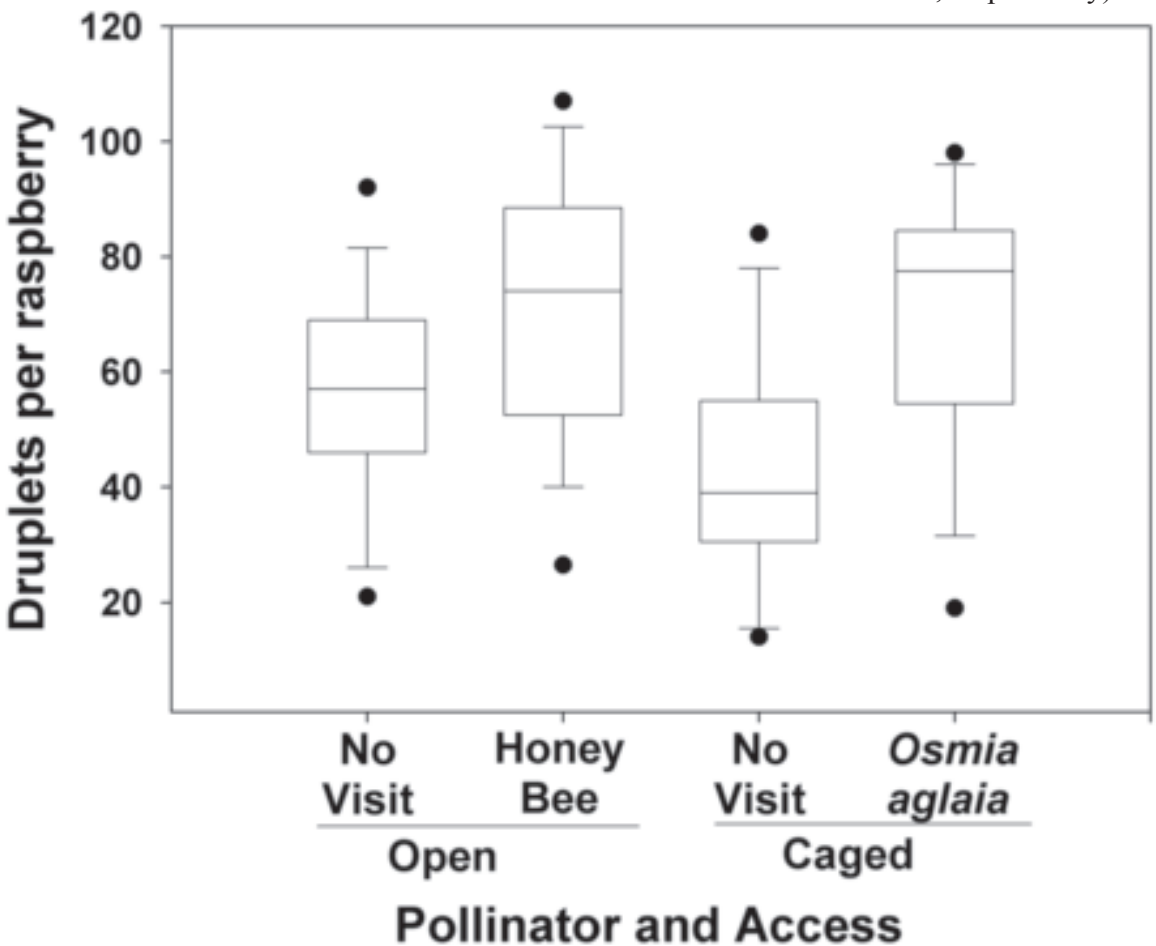

Fig. 3. Drupelet counts of individual 'K81-6' red raspberries that resulted from unvisited flowers, or flowers accessible to either honey bees or else the bee Osmia aglaia, Bear Lake, Utah, Summer 2002. The box diagram depicts the 9th and 95th percentile (dots), 10th and 90th percentile (stems), 25th and 75th percentile (box), and median (cross-bar). 
blackberry flowers, O. aglaia worked flowers at a similar pace (6 flowers/min, 12 females visiting 57 flowers), in all cases standing atop the column of pistils and pivoting for nectar, as was seen at red raspberry.

Pollination. Significantly larger red raspberry fruit resulted when flowers were accessible to either $O$. aglaia or honey bees than when bees were excluded (Fig 2). Drupelet counts of fruit of 'K81-6' in Utah varied significantly with treatment $\left(\mathrm{F}_{[2,157]}=15.6, P\right.$ $\leq 0.0001)$ (Fig. 3). Flowers bagged to exclude bees yielded fruit possessing $20 \%$ to $40 \%$ fewer drupelets than those openly accessible to either O. aglaia or honey bees ( 80 fruit each, $\mathrm{F}=31$, $P \leq 0.0001)$. There was a minor detrimental caging effect ( $43 \pm 21$ vs. $57 \pm 21$ drupelets on bagged laterals in and outside of the cage, $t_{[78]}=2.96, P=0.004$ ) that might have biased drupelet count comparisons against $O$. aglaia. Nevertheless, the two bee species proved to be equivalent pollinators as measured by the resulting drupelet counts of fruit $(69 \pm 24 \mathrm{vs} .71$ \pm 24 drupelets, $\mathrm{F}=0.1, P=0.76$ ) (Fig. 3).

Fresh fruit weights of the other tested red raspberry likewise varied with treatment $\left(\mathrm{F}_{[2,99]}\right.$ $=11.4, P \leq 0.0001$ ) (Fig. 4). Ripe fruit from 'Canby' flowers accessible to O. aglaia or to honey bees were on average $30 \%$ heavier than those bagged to exclude bees $(\mathrm{F}=22.6, P \leq$ $0.0001)$. Fruit of comparable weight resulted when flowers were open to visitation by either bee species $(1.91 \pm 0.37 \mathrm{~g}$ vs. $1.94 \pm 0.48 \mathrm{~g}$, respectively, $\mathrm{F}=0.1, P=0.7)$. There was no caging effect $\left(t_{[33]}=0.11, P=0.9\right)$. Although 'Canby' fruit were of comparable weight regardless of bee species, those caged with $O$. aglaia in Utah were exposed to sparser bee densities than those exposed to honey bees

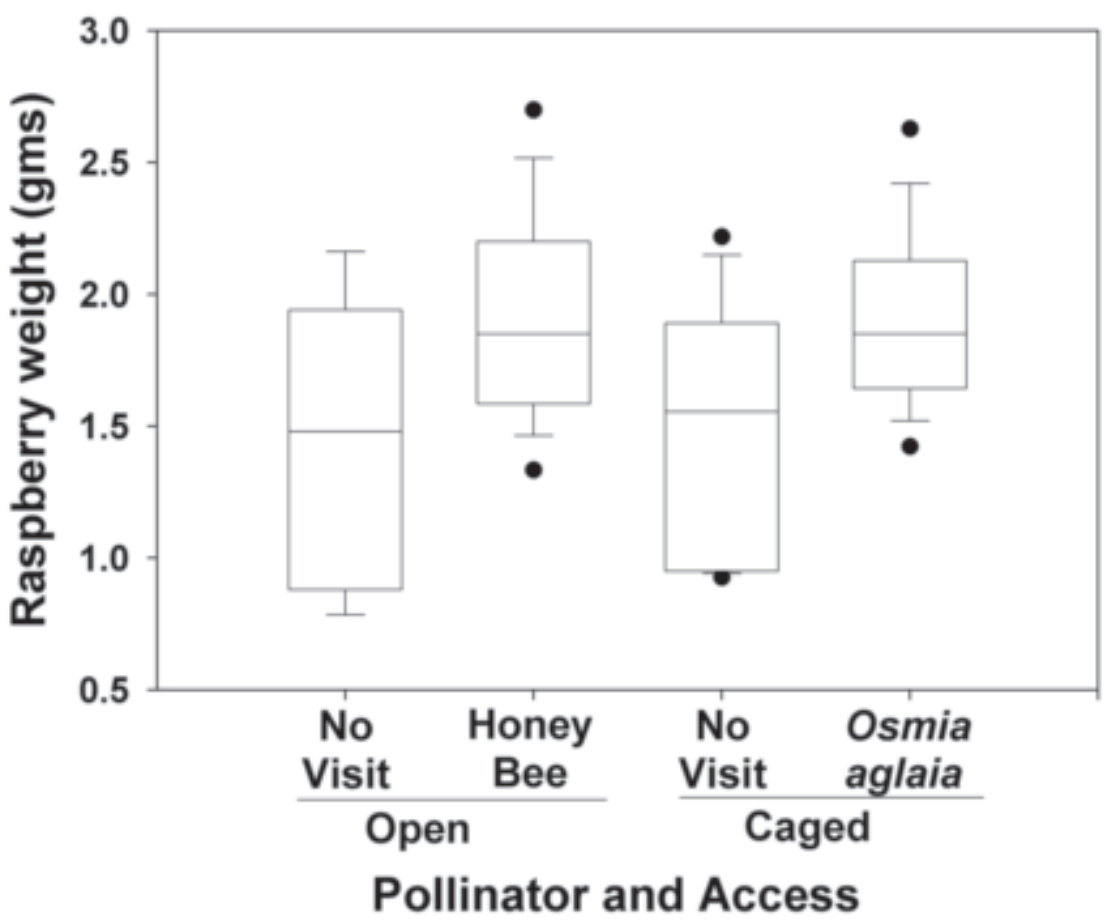

Fig. 4. Weights of individual red raspberries 'Canby' that resulted from unvisited flowers, or else flowers accessible to either honey bees or else the bee Osmia aglaia, Bear Lake, Utah, Summer 2003. The box diagram depicts the 9th and 95th percentile (dots), 10th and 90th percentile (stems), 25th and 75th percentile (box), and median (cross-bar). outside the cage ( 12 vs. 17 bees censused per $10 \mathrm{~m}$ of row, respectively).

\section{Discussion}

Floral visitation by honey bees or O. aglaia improved fruit size by 'K81-6' and 'Canby' red raspberries in terms of drupelet counts and fresh fruit weights (Figs. 2, 3, and 4). red raspberry production have precedent with earlier studies of eight other cultivars, including 'Willamette' (Kühn, 1987), 'Puyallup' and 'Sumner'(Shanks, 1969), 'Festival'(Chagnon et al., 1991), and 'Malling Promise', 'Malling Jewel', 'Norna', and 'Veten' (Wieniarska, 1987). Cultivated red raspberries are self-fertile and typically have the same high probability of setting fruit with or without bees. However, senescing stamens often fail to curl and passively contact stigmas of the central pistils (Nybom, 1986). Smaller, misshapen, sometimes crumbly fruit result (Fig. 2). Compared with flowers accessible to bees, not only were fruit of unvisited 'Canby' flowers 30\% lighter on average, but 11 of the 35 fruit from the no-visit treatment were $>2$ SD lighter than the average fruit from bee-visited flowers (which were all within 2 $\mathrm{SD}$ of the mean). These grossly undersized fruit are difficult to pick and unacceptable for fresh market sales.

Honey bees are the only pollinator currently managed for Rubus pollination. They are generally valuable pollinators for cane fruit (Chagnon et al., 1991; Free, 1993; Kühn, 1987; Shanks, 1969; Wieniarska, 1987) if sufficiently abundant and active. Individual honey bees are inferior to bumble bees for Rubus pollination, however, as honey bees deliver fewer pollen These benefits of bee visitation for cultivated grains to stigmas during each visit and require warmer weather to fly (Gyan and Woodell, 1987; Willmer et al., 1994). Several sequential floral visits by honey bees seem necessary to achieve full fruit size (Chagnon et al., 1991; Eaton et al., 1968). The underlying cause is not known: perhaps stigmas become receptive sequentially over several days (Eaton et al., 1968), perhaps individual honey bee foragers frequently deposit too few pollen grains during any one visit (Gyan and Woodell, 1987; Willmer et al., 1994), so that pollen must be accumulated over several visits (Chagnon et al., 1991), or perhaps several visits ensures that at least one of the foragers bears pollen and makes good contact with the central pistils. Honey bees actively collecting pollen can be less frequent than honey bees seeking only nectar from red raspberry flowers, but visits from pollen-foragers result in fruit that are $30 \%$ heavier than those visited by nectar-foragers (Chagnon et al., 1991). Pollen-foraging honey bees likewise exceed nectar foragers for their pollination value in cranberries (Vaccinium macrocarpon Ait.) (Cane and Schiffhauer, 2001). In both crops, nectar-foragers often sidework the flowers, in the case of raspberries by walking in a circle probing the ring of nectaries but often missing contact with the central pistils, resulting in incomplete pollination. In contrast, we found that $O$. aglaia females (and males too) observed at red raspberry and blackberry flowers always contacted the central pistils, the foraging females standing astride the center of the flower and pivoting to reach the nectaries. Also in contrast with honey bees, foraging female $O$. aglaia always simultaneously collected pollen, the behavior associated with superior pollination. Their tempo of floral visitation is very comparable to that of the honey bee. The foraging behaviors of $O$. aglaia are seen to be more consistently optimal for Rubus pollination than those of honey bees.

Only two other manageable species of bees have been considered for pollination of cultivated Rubus, both nonsocial cavity-nesting members of Osmia (Osmia). In Italy, O. cornuta and honey bees were flown in different plastic houses with blooming blackberries ('Black Satin' and 'Thornless Evergreen'). Fruit production was clearly enhanced, with heavier fruit bearing more drupelets resulting from pollination by either bee species compared to flowers from unvisited controls (Pinzauti et al., 1997). In Canada, O. lignaria was tried with cultivated Rubus; females largely ignored red raspberry in favor of blackberry, and reproduced poorly, possibly because their emergence had been so long delayed to match bloom phenology (Cory Sheffield, personal communication). Both bee species have single adult generations that fly in early spring. Where open grown cane fruit flower in June, managing overwintering and later emergence of these two early spring Osmia species is challenging or impractical using current methodologies. Although it also overwinters as an adult, $O$. aglaia requires a week of incubation at summer temperatures before it is ready to fly (R. von der Hellen, personal communication). In southern Oregon, 
its June flight coincides with bloom of cultivated raspberries and blackberries, making its adult management the easiest to schedule among the nonsocial cavity-nesting bees thus far considered for Rubus pollination.

\section{Literature Cited}

Burgett, M. 2004.2003 Pacific Northwest honey bee pollination survey. The Speedy Bee 33(7):8-9.

Cane, J.H. 1997. Ground-nesting bees: The neglected pollinator resource for agriculture. In: K.W. Richards (ed.). Proc. Intl. Symp. Pollination. 7. Pollination: From theory to practice. Acta Hort. 437:309-324.

Cane, J.H. and D. Schiffhauer. 2001. Pollinator genetics and pollination: do honey bee colonies selected for pollen-hoarding field better pollinators of cranberry Vaccinium macrocarpon? Ecol. Entomol. 26:117-123.

Chagnon, M., J. Gingras, and D. de Oliveira. 1991. Honey bee (Hymenoptera: Apidae) foraging behavior and raspberry pollination. J. Econ. Entomol. 84:457-460.

Eaton, G.W., H.A. Daubeny, and R.C. Norman. 1968. Pollination techniques for red raspberry breeding programs. Can. J. Plant Sci. 48:342-344.

Free, J.B. 1993. Insect pollination of crops, 2nd ed. Academic Press, New York.

Gyan, K.Y. and S.R.J. Woodell. 1987. Analysis of insect pollen loads and pollination efficiency of some common insect visitors of four species of woody Rosaceae. Funct. Ecol. 1:269-274.

Hansen, R.W. and E.A. Osgood. 1983. Insects visiting flowers of wild red raspberry Rubus idaeus in spruce-fir forested areas of eastern Maine. Entomol. News. 94:147-151.

Hippa, H., S. Koponen, and O. Osmonen. 1981. Flower visitors to the cloudberry, Rubus chamaemorus, in northern Fennoscandia. Ann. Univ Turk Ser a II Biol-Geogr-Geol. 66:44-54.

Jennings, D.L. 1988. Raspberries and blackberries: their breeding, diseases and growth. Academic Press, New York.

Kühn, B.F. 1987. Bestovning afhindbaersorten 'Willamette'. Tidsskrift for Planteavl. 91:85-88.

MacKenzie, K.E. and M.L. Winston. 1984. Diversity and abundance of native bee pollinators on berry crops and natural vegetation in the lower Fraser Valley, British Columbia. Can. Entomol. 116:965-974.

McGregor, S.E. 1976. Agricultural handbook 496: Insect pollination of cultivated crop plants. U.S Gov't. Printing Off., Wash., D.C.

Medler, J.T. 1967. Biology of Osmia in trap nests in Wisconsin (Hymenoptera: Megachilidae). Ann. Entomol. Soc. Amer. 60:338-344.

Mitchell, T.B. 1962. Bees of the eastern United States. vol. 2. N.C. Agr. Expt. Sta. Tech. Bul. 152

Nybom, H. 1986. Active self-pollination and pollen stainability in some Rubus cultivars. J. Hort. Sci. 61:49-55.

Pelletier, L., A. Brown, B. Otrysko, and J.N. McNeil. 2001. Entomophily of the cloudberry
(Rubus chamaemorus). Entomol. Expt. Appl. 101:219-224.

Pinzauti, M., D. Lazzarini, and A. Felicioli. 1997. Preliminary investigation of Osmia cornuta Latr. (Hymenoptera, Megachilidae) as a potential pollinator for blackberry (Rubus fruticosus L.) under confined environment. Acta Hort 427:329-333.

SAS Institute. 1989. SAS/STAT user's guide, version 6,4 th ed. SAS Institute, Cary, N.C.

Schmidt, J.O., S.C. Thoenes, and M.D. Levin. 1987. Survival of honey bees, Apis mellifera (Hymenoptera: Apidae), fed various pollen sources. Ann. Entomol. Soc. Amer. 80:176-183.

Shanks, C.H.J. 1969. Pollination of raspberries by honeybees. J. Apicult. Res. 8:19-21.

Sokal, R.R. and F.J. Rohlf. 1995. Biometry. 3rd ed. W. H. Freeman, New York.

Whitney, G.G. 1984. The reproductive biology of raspberries and plant-pollinator community structure. Amer. J. Bot. 71:887-894.

Wieniarska, J. 1987. The role of pollinating insects in fruiting of some red raspberry cultivars. Fruit Sci Rpt. (Skierniewice) 14:65-70.

Willmer,P.G.,A.A.M. Bataw, and J.P.Hughes. 1994 The superiority of bumble bees to honeybees as pollinators-Insect visits to raspberry flowers. Ecol. Entomol. 19:271-284.

Winston, M.L. and L.H. Graf. 1982. Native bee pollinators of berry crops in the Fraser Valley of British Columbia (Canada). J. Entomol. Soc. B.C. 79:14-20. 